\title{
Section IV
}

\section{Tools for Training and Development}

Here is where the rubber hits the road. The materials that follow are attempts to translate theory into practice. Much of what we read (and do) for training our colleagues to be more effective teachers is rough and untidy. It often seems simplistic. But that is the state of the art and it will always be so to some degree. In the classroom, in the faculty lounge and at the sylvan retreats where workshops are held, we must finally decide what to do on Monday.

The Erickson and Erickson team have tackled the unenviable task of identifying critical principles of learning and showing how they can be implemented in writing course objectives, teaching and testing. Their examples have been used in a workshop format designed by Bette Erickson and Sher Reichmann. Similarly, "The Design of Intellectual Experience" is an abstraction of an approach to course design that Don Finkel and Steve Monk use in their summer workshop for faculty.

The next four pieces - on class discussions, charismatic teaching, the first day of class and developing consciousness of and solutions to women's special needs in academia - all contain explicit suggestions for workshop designs. They are based on successful practice, but require sensitive adaptation to particular settings. A rule from microteaching design applicable here is: know what your client wants before you offer help! A good idea (but hardly a rule) is: call these folks and 
discuss your setting and approach before adapting these designs. Learning is a peculiar business - it resists mass production.

The last three articles are a smorgasbord of suggestions, representing the wide range of practice which we call professional and organizational development. Linc Fisch gives us an introduction to some delightfully heuristic filmic devices for training. Marina Estabrook turns the spotlight on what is often taken for granted - the physical space in which we teach. And a team from Minnesota illustrates the effects of yet another approach to individualized consultation with faculty - the teaching/learning strategy recalled a century ago in the image of Mark Hopkins sitting opposite a single student on the end of that New England log. 